\title{
Research Paper: Scientific Achievements of Medical Journals in Occupational Accidents
}

\author{
$\operatorname{Aram~Tirgar~}^{1^{*}}$ (D), Zahra Aghalari² ${ }^{2}$ \\ 1. Social Determinants of Health Research Center, Health Research Institute, Babol University of Medical Sciences, Babol, Iran. \\ 2. Student Research Committee, Babol University of Medical Sciences, Babol, Iran.
}

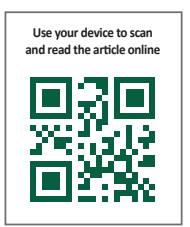

Citation: Tirgar A, Aghalari Z. Scientific Achievements of Medical Journals in Occupational Accidents. Health in Emergencies and Disasters Quarterly. 2018; 3(4):179-184.

Funding: See Page 183

(c) Copyright: The Author(s)

Article info:

Received: 05 Jan. 2018

Accepted: 20 May 2018

Available Online: 01 Jul. 2018

\section{Keywords:}

Occupational health, Safety, Journal

\section{ABSTRACT}

Background: Occupational accidents are the second cause of occupational fatality in Iran and are among the major health, social, and economic risk factors. Since the publication of scientific articles in the field of occupational accidents reflects the concern of researchers to this important issue, the present study aimed to evaluate the scientific achievements in the field of occupational accidents in the journals of Iranian medical sciences universities.

Materials and Methods: The current cross-sectional study was carried out by content analysis method on Persian journals of Iranian medical sciences universities from 2007 to 2016. For data extraction, a researcher-made data collection form tailored to the research objectives was used. Data analysis was performed using descriptive statistics indices.

Results: Assessing a total of 52158 articles extracted from 5226 issues of 147 journals published by 49 medical sciences universities showed that the number of scientific articles in the field of occupational accidents was 259 (0.4\% of the total articles). A growing trend was observed in the number of articles during the 10-year study from 12 articles in 2007 to 52 in 2016. The content analysis of the articles showed that the majority of the articles $(n=85$, $32.8 \%$ ) were about industrial accidents followed by occupational accidents among healthcare providers $(\mathrm{n}=48,18.5 \%)$. Most articles $(\mathrm{n}=254,98 \%)$ were original research, and the research tools in most of the papers $(\mathrm{n}=214,82.6 \%)$ were questionnaire and checklist.

Conclusion: Although the publication of a high number of articles on occupational accidents in the journals of medical sciences universities indicates the attention of experts to the health of the workforce, research in this area is far from enough. Therefore, enhancing the attention of experts, especially the ones in occupational health, occupational medicine, ergonomics, and safety areas seems necessary.

\section{Introduction}

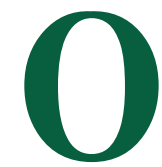

ccupational incidents are among undesirable consequences of the development of modern industries and technologies
[1]. Occupational accidents and hazards occur in the workplace and lead to fatal or non-fatal injuries. Most occupational accidents can be prevented, but if occur, they can lead to disability, lower incomes, and changes in the quality of life of workers and their families. These

*Corresponding Author:

Aram Tirgar, PhD

Address: Social Determinants of Health Research Center, Health Research Institute, Babol University of Medical Sciences, Babol, Iran

E-mail:a.tirgar@mubabol.ac.ir 
accidents can also have social and economic effects and harms productivity $[2,3]$.

In fact, occupational accidents as the third leading cause of death worldwide and the second cause of death in Iran, are the most important health, social, and economic risk factors in the industrial communities [4]. Studies show that millions of occupational accidents occur annually worldwide [5]. According to the statistics released by the International Labor Organization (ILO), one person loses his or her life due to occupational accidents every 15 seconds [6]. The ILO also stated that about two million people die in the workplace, and more than 300 million people get injured every year $[7,8]$.

In Iran, according to the statistics reported by the Social Security Organization (SSO) in 2003, 268 people died from 14114 accidents in the workplaces monitored by the SSO. Also, according to one of the official reports of the SSO in 2009, a total of 21740 people were injured due to work-related accidents in Iran, of them, 110 died and 234 got disabled $[9,10]$. According to statistics issued by the Iranian Legal Medicine Organization, despite the higher number of casualties caused by occupational accidents in 2011 compared to the past ten years, this trend continued to rise by $19.1 \%$ in 2012 . Therefore, occupational accidents are considered as a growing problem in public health in Iran and around the world [11].

Preventing occupational accidents due to their significant losses is very important. An essential step in controlling and dealing with accidents is collecting and analyzing the related data. Managers need a full knowledge about the underlying causes of the accidents and their consequences, to make an informed decision in accidents $[12,13]$. In many countries, research on occupational accidents is a legal requirement after occurrence. In these research studies, various related information such as accident scenarios, root causes, contributing causes, and actual and potential consequences of accidents are published [14]. The occupational accidents have consequences not only for the society and public health, but also for personal and family lives. One way to explain the importance of events is to draw the consequences and identify the causes and prevention methods through research and publication of scientific papers. In order to make any scientific and rational decision on the prioritization or the causes of events, we should access to research findings. This study aimed to monitor the scientific production in the field of occupational accidents in Persian journals of medical universities in Iran.

\section{Materials and Methods}

This descriptive study was carried out on a cross-sectional basis during a period of 10 years (2007-2016) among all Persian journals of the 49 medical sciences universities in Iran. The Journals which later changed into English were excluded from the study. Each published paper in an issue, available in the website of the journals were reviewed. The title of papers and, if necessary, abstracts and keywords addressing occupational hazards and accidents were evaluated. This method, scientometrics (one of the most common methods for evaluating scientific activities), is used in many studies $[15,16]$.

Data collection was done through a census method, using a researcher-made checklist. The study variables were universities, Persian scientific journals of each university, the published papers during 2007-2016, and the number of published papers related to occupational accidents. The criterion for choosing papers was the use of the terms in the title, abstract, or keywords. After identifying papers on occupational accidents, their full texts were examined. Then, using content analysis method, the required information such as subject, type of study, study methods, data collection tool and the study population were gathered $[17,18]$. For analyzing the collected data, descriptive statistics like mean or median were used.

\section{Results}

We studied 147 Persian journals issued by 49 medical sciences universities. The number of papers published in

Table 1. Frequency of the papers and issues published by Iranian medical universities during 2007-2016

\begin{tabular}{|c|c|c|c|c|c|c|c|c|c|c|c|}
\hline \multirow{2}{*}{ Variable } & \multicolumn{10}{|c|}{ Publication Year } & \multirow{2}{*}{ Total } \\
\hline & 2007 & 2008 & 2009 & 2010 & 2011 & 2012 & 2013 & 2014 & 2015 & 2016 & \\
\hline Number of published issues & 258 & 272 & 308 & 365 & 447 & 580 & 776 & 633 & 766 & 821 & 5226 \\
\hline Number of published papers & 2991 & 3022 & 3069 & 3996 & 4815 & 6247 & 6854 & 6270 & 7635 & 7259 & 52158 \\
\hline $\begin{array}{l}\text { Papers related to occupational } \\
\text { accidents }\end{array}$ & 12 & 7 & 19 & 13 & 23 & 34 & 34 & 33 & 51 & 52 & 259 \\
\hline
\end{tabular}


Table 2. Characteristic of Persian papers from medical universities regarding occupational accidents during 2007-2016

\begin{tabular}{|c|c|c|}
\hline Scales & Answer & $\mathbf{N}$ \\
\hline \multirow{6}{*}{$\begin{array}{l}\text { Expertise of corre- } \\
\text { sponding authors }\end{array}$} & Occupational health & 148 \\
\hline & Nursing and midwifery & 18 \\
\hline & Health, safety and environment & 17 \\
\hline & Occupational medicine & 10 \\
\hline & Health services management & 8 \\
\hline & $\begin{array}{c}\text { Other (e.g. epidemiology, health economics, health education, biostatistics, medical } \\
\text { education and ergonomics) }\end{array}$ & 58 \\
\hline \multirow{6}{*}{ Subject of papers } & Industries and mines & 85 \\
\hline & Healthcare jobs & 48 \\
\hline & Road traffic accidents & 31 \\
\hline & Case study in various occupations & 20 \\
\hline & Construction industry & 14 \\
\hline & $\begin{array}{l}\text { Others (e.g. occupational hazards of women or administrative staff, animal-related work } \\
\text { accidents, case studies in various occupations) }\end{array}$ & 61 \\
\hline \multirow{2}{*}{ Type of paper } & Original paper & 254 \\
\hline & Review paper & 5 \\
\hline \multirow{6}{*}{ Data collection tool } & Questionnaire & 138 \\
\hline & Researcher-made checklist & 62 \\
\hline & Questionnaire and checklist & 14 \\
\hline & Experiment or examination & 10 \\
\hline & Examination and questionnaire & 7 \\
\hline & Others (names of the tests or applications) & 28 \\
\hline
\end{tabular}

these journals were 20346 from 5226 issues. The highest number of journals belonged to Shahid Beheshti University of Medical Sciences and Tehran University of Medical Sciences $(n=14)$. The examination of the published papers showed that the absolute frequency of the papers and issues published during 2007-2016, except for one year, has steadily increased over this period (Table 1). Among all the papers and sections examined (title, abstract, and keywords), 259 papers were found relevant to occupational accidents. Those were published by 39 universities, in which Iran University of Medical Sciences with 58 papers was ranked first, and Tehran University of Medical Sciences and Yazd University of Medical Sciences with 35 and 30 papers were ranked as the second and third, respectively.

Analysis of the papers contents showed that 85(32.8\%) papers were about hazards and accidents in industrial occupations and 48(18.5\%) about hazards and accidents in healthcare jobs. In terms of type of the article, most papers $(254,98 \%)$ were original works and the data collection tool of most of them (214) were questionnaire and or checklist. Table 2 presents the detail information.

\section{Discussion}

The results of our study on scientific papers published by Iranian medical universities showed that more than 52000 papers were published, over a period of 10 years from the beginning of 2007 to the end of 2016. Of these, only $259(0.4 \%)$ had studied the occupational accidents. Considering that accidents in Iran have been one of the serious health threats in recent decades (e.g. car accidents in Iran are the second leading causes of death accounting for $12.5 \%$ of mortality), while this factor is in the tenth place, internationally $[19,20]$. 
On the one hand, published papers are among the main channels that reflect the activity and attention of the scientific community to any topic and provide sufficient and reliable information to make decisions and implement interventions to reduce accidents [21, 22]. This amount of publication can be considered as a kind of neglect of scientific follow-up on occupational accidents, and the lack of serious attention to occupational health hazards. In other words, the research priorities of the faculty members of universities, including medical schools, should be reconsidered, and the research on occupational accidents should have a high priority.

Obviously, in light of scientific and accurate information, managers and policymakers will be able to make informed decisions and provide instigating measures to ensure health, prevent accidents, and promote the people's health, including labor force in the society. In line with that, Salehi et al. [23] reported that conducting epidemiological studies on work-related accidents is superior to other types of research studies because such studies can identify the causes of occupational accidents. Also, these studies increase the awareness of society and policy makers about the extent of impact and importance of accidents. This issue also has been highlighted in the study of Amani et al. [19] investigating the trend of the major causes of mortality in Iran.

The content analysis of 259 papers on occupational hazards or accidents showed that most papers were about hazards and accidents in industrial occupations and healthcare jobs. Assigning such a contribution from research articles to each subject is, to some extent, a reflection of the importance of these events among other occupational groups. Given that $58 \%$ of people in the world spent about one-third of the life in the workplaces for, and occurrence of about 350000 job-related and fatal accidents, along with 264 million non-fatal work-related accidents globally [9], more attention should be paid to the accidents and their adverse personal, economic, social and familial consequences.

Occupational accidents in different industrial occupations vary according to the type of occupation, environment and the used equipment, but one common factor in all occupational accidents is their irreparable effects on the health of workers, assets, materials, and property. Identifying the causes and effective factors in creating accidents is a major preventive component. An important way to prevent industrial accidents is the analysis of accidents by researching and writing articles in the related field which help to understand the effective and contributing factors in the occurrence of occupational accidents [24]. In fact, extensive efforts by researchers, while identifying the causes of accidents, can describe and analyze industrial events and by better understanding and predicting accidents, could finally provide safer ways of prevention.

In most studies on occupational accidents in health care jobs such as medicine and nursing (18 papers), injuries caused by needles and sharp objects have been reported as one of the most important occupational hazards [25, 26]. These injuries can significantly result in health problems and psychological stress in healthcare providers [27]. Exposure to blood borne pathogens due to needles tick incidence is a potential threat to healthcare workers. Needles tick injuries result in significant economic and human costs. In England, for example, such cost was estimated around 500000 pounds a year [28]. Given the importance of such injuries, it is possible to improve the knowledge and performance of health workers by publishing articles in this area.

According to the results, published papers were mostly (98\%) original research. This is in line with the findings of some previously conducted studies. For example, Ghahnavieh et al. [29] reported that the most of articles $(85.7 \%)$ were original research and others were review papers $(7.4 \%)$. This finding, in line with the actual mission of the scientific/research journals in Iran, shows the authors' attention to the production of science in the form of original research. Also, more than half of the study papers $(86.2 \%)$ was performed by a questionnaire and checklist. In the study of Ghahnavieh et al. [29], in most of articles (87.4\%), information gathering tools were either checklist (44\%) or questionnaire (43.4\%), and only two articles used the interview method.

\section{Conclusion}

The rate of publication of papers about occupational accidents in medical journals is very low, despite the growing trend of occupational hazards. Therefore, relevant measures should be taken to draw specialists' attention toward areas, such as occupational health, occupational medicine, safety and ergonomics.

One of the strong points of the current study is the analysis over a relatively broad range of time (10 years), and a pretty large collection of articles (over 50000 articles) from the journals of medical schools, in spite of some limitations in the studied variables and evaluation of non-research but specialized journals, as well as evaluating journals affiliated with the Iranian Ministry of Science. 


\section{Ethical Considerations}

\section{Compliance with ethical guidelines}

This study was approve by the ethics committee of Babol University of Medical Sciences under code no. MUBABOL.REC.1392.17.

\section{Funding}

This research did not receive any specific grant from funding agencies in the public, commercial, or not-forprofit sectors.

\section{Conflict of interest}

The authors certify that they have no affiliation with or involvement in any organization or entity with any financial interest, or non- financial interest in the subject matter or materials dismissed in this manuscript.

\section{Acknowledgments}

The authors would like to thank all professors, students and scholars whose works were used as a source of conducting this study.

\section{References}

[1] Hoveidi H, Givehchi S, Hazrati S, Ghanbari N. [Incidence rate of occupational accidents in an Iranian sugar plant from 2000 to 2011 (Persian)]. Journal of Health. 2013; 4(2):180-88.

[2] Zarei E, Dormohammadi A. [Accidents analysis in a Disaster and Emergency Medical Management Center (Persian)]. Journal of Safety Promotion and Injury Prevention. 2015; 3(3):191-98.

[3] Hajizadeh R, Malakoti J, Beheshti M, Khodaparast A, Mehri A, Akbaezadeh A, et al . [Epidemiological study of Qom construction accidents and provide an algorithm for accidents recordation (Persian)]. Iran Occupational Health Journal. 2015; 12(2):70-8

[4] Hasoumi M, Jouyani Y, Asadi H, Khakian M, Aryankhesal A. [Staff occupational accidents and absence in hospitals of Tehran and Iran universities of medical sciences (Persian)]. Occupational Medicine Quarterly Journal. 2016; 7(4):4-13.

[5] Ghahramani A, Abbasi A. [Assessment of the relationship between occupational accident experience and personal and job factors in tar paper manufacturing companies (Persian)]. Iran Occupational Health Journal. 2016; 12(6):48-57.

[6] Arab M, Hoseini M, Panahi M, Khalili Z. [Nursing occupational hazards of the emergency department in teaching hospitals affiliated to Tehran University of Medical Sciences (Persian)]. Journal of Hospital. 2015; 14(2):35-48.
[7] Janmohammadi N, Tirgar A, Babazadeh A, Sarvi F. [Epidemiologic study of bone and soft tissue injuries resulting from occupational accidents in hospitalized patients of shahid beheshti hospital in Babol city during 2010-2012 (Persian)]. Journal of Ilam University of Medical Sciences. 2015; 23(2):36-43.

[8] Nazari J, Mosaferi M, Alamshahi AH. [The study of rate and cause of occupational accidents occurred throughout the overhaul program in one of petroleum industries (2001-2010) (Persian)]. Depiction of Health. 2013; 4(3):18-23.

[9] Atrkar Roushan S, Alizadeh SS. [Estimation of economic costs of accidents at work in Iran: A case study of occupational accidents in 2012 (Persian)]. Iran Occupational Health Journal. 2015; 12(1):12-9.

[10] Amiri M, Ardeshir A, Soltanaghaei E. [Analysis of high risk occupational accidents in construction industry using datamining methods (Persian)]. Iran Occupational Health Journal. 2014; 11(4):31-43

[11] Nekooi Moghadam M, Amiresmaili MR, Mirshahi F, Sefidbor N, Sharifi T, Ghorbani R, et al. [The rate of occupational hazards and the effective factors in nurses of selected hospitals of Kerman in 2011 (Persian)]. Journal of Health and Development. 2013; 2(3):235-49.

[12] Hosseini Kebria SS, Mohammadi Golafshani E, Kashefi Alas M, Jozi SA. Predicting the occupational accidents of Tehran's oil Refinery based on HSE using fuzzy logic model . Iran Occupational Health Journal. 2014; 11(6):43-54.

[13] Omidvari M, Gharmaroudi MR. [Analysis of human error in occupational accidents in the power plant industries using combining innovative FTA and Meta-Heuristic Algorithms (Persian)]. Health and Safety at Work. 2015; 5(3):1-12.

[14] Beheshti M, Rahat R, Davoodi A, Hoseon Alizadeh F, Azrah K, Hajizadeh R. [Investigation of the most important direct cause of occupational accidents based on the Pareto Chart (Persian)]. Iran Occupational Health Journal. 2015; 12(3):38-45.

[15] Tirgar A, Aghalari Z. [Tendency to religious issues in scientific outputs of medical sciences (Persian)]. Islam and Health Journal. 2014; 1(3):35-40.

[16] Tirgar A, Aghalari Z. [Assessing scientific outputs of Human Sciences Journals regarding resistive economy (Persian)]. Caspian Journal of Scientometric. 2015; 2(2):16-23.

[17] Tirgar A, Aghalari Z. [A content analysis of economic in scientific outputs of medical sciences (Persian)]. Community Health. 2015; 2(4):223-27.

[18] Aghalari Z, Tirgar A. Topics of disasters in scientific outputs of medical sciences: A cross-sectional study. Health in Emergencies and Disasters. 2017; 2(2):47-52. [DOI:10.18869/ nrip.hdq.2.2.47]

[19] Amani F, Kazemnejad A, Habibi R, Hajizadeh E. [Pattern of mortality trend in Iran during 1970-2009 (Persian)]. Journal of Gorgan University of Medical Sciences. 2011; 12(4):85-90

[20] Entezami N, Hashemi-Nazari SS, Soori H, Khosravi A, Ghadirzadeh MR. [Epidemiology of fatal road traffic accidents in northern provinces of Iran during 2009 to 2010 (Persian)]. Journal of Safety Promotion and Injury Prevention. 2015; 3(1):1-8

[21] Fereshtehnejad SM, Motevalian SA, Moradi Lakeh M, Aghili S, Shafiee Sabet A. [Comparison of the qualitative and 
quantitative indexes of scientific medical iournals affiliated to Iran University of Medical Sciences with Iranian exemplary medical journals during 2008-2010 (Persian)]. Iran University of Medical Sciences. 2010; 17(77):40-54.

[22] Khorshidi A, Ainy E, Sabagh M, Soori H. [Traffic injury data collection in Iran, challenges and solutions (Persian)]. Journal of Safety Promotion and Injury Prevention. 2015; 3(1):35-42.

[23] Salehi M, Imani M, Zayeri F, Vahabi N, Pirhosseini H, Arji M. [Bayesian model for work-related accidents in Iran: 2009 (Persian)]. Journal of Health Administration. 2013; 16(51):30-42.

[24] Soltanzadeh A, Mohammadfam I, Moghim beygi A, Akbarzadeh M. [Studying disabling occupational accidents in the construction industry during two years (Persian)]. Journal of Occupational Hygiene Engineering. 2014; 1(2):57-66.

[25] Javadzadeh H, Badrian S, Reisi M, Askari N, Meshkati M, Badrian M. [A study of the frequency of occupational injuries and knowledge of standard precautions among laboratory staff and nurses (Persian)]. Journal of Health System Research. 2015; 11(4):671-6.

[26] Ghanei Gheshlagh R, Zahednezhad H, Shabani F, Hameh M, Ghahramani M, Farajzadeh M, et al . [Needle sticks injuries and its related factors among nurses (Persian)]. Iranian Journal of Neonatology. 2014; 27(89):21-29.

[27] Sayehmiri K, Mohammadi E, Mohammadi I, Sayehmiri F. [Epidemiology of needle sticks and sharps injuries in healthcare workers in Iran: A systematic review and meta-analysis (Persian)]. Iran Occupational Health Journal. 2014; 11(5):93-103.

[28] Shoghli A, Mousavi Nasab N, Ghorchian F, Masoumi H, Momtazi S. [Study of the Needle Sticks Injury (NSI) among the Zanjan Educational Hospitals Staff (Persian)]. Journal of Zanjan University of Medical Sciences. 2013; 21(85):131-41.

[29] Ghahnavieh H, Movahedi F, Yarmohamadian MH, Ajami S. Content and citation analysis of articles published in the journal of "Health Information Management" (Persian)]. Health Information Management. 2011; 8(1):86-96. 